\title{
Carolina Foxtail (Alopecurus carolinianus): Susceptibility and Suitability as an Alternative Host to Rice Blast Disease (Magnaporthe oryzae [formerly M. grisea])
}

\author{
Y. Jia and D. Gealy, Dale Bumpers National Rice Research Center, United States Department of Agriculture- \\ Agricultural Research Service (USDA-ARS), Stuttgart, AR 72160; M. J. Lin and L. Wu, University of Arkansas \\ Rice Research and Extension Center, Stuttgart 72160; and H. Black, USDA-ARS, Dale Bumpers National Rice Re- \\ search Center
}

\begin{abstract}
Jia, Y., Gealy, D., Lin, M. J., Wu, L., and Black, H. 2008. Carolina foxtail (Alopecurus carolinianus): Susceptibility and suitability as an alternative host to rice blast disease (Magnaporthe oryzae [formerly M. grisea]). Plant Dis. 92:504-507.

Carolina foxtail (Alopecurus carolinianus) has not been reported to host Magnaporthe oryzae. A collection of Carolina foxtail obtained from several Arkansas locations over a 4-year period was inoculated with four races of the fungus under greenhouse conditions and, in all cases, inoculation resulted in the formation of irregular, yellow and brown lesions without obvious gray centers that are characteristic for blast on rice. Differences in these lesions were not observed among our collection. These lesions appeared to differ from typical blast lesions on inoculated rice leaves but were evident following artificial inoculation of Carolina foxtail in the greenhouse. $M$. oryzae races that differed in pathogenicity toward rice cultivars also displayed differences in lesion development on Carolina foxtail. The most virulent race on rice cultivars also produced lesions most rapidly on Carolina foxtail. These lesions developed more quickly on Carolina foxtail than on the most susceptible rice cultivars tested, including a susceptible California cultivar, M202. M. oryzae isolates cultured from these lesions in the infected Carolina foxtail caused typical disease symptoms of blast on inoculated rice cultivars. We suggest that Carolina foxtail is a new and previously unrecognized host for the blast pathogen.
\end{abstract}

Additional keywords: Pyricularia grisea, Oryza sativa

Rice (Oryza sativa L.) is one of the most important food crops in the world. One of the most important diseases of rice worldwide is blast, caused by the fungal pathogen Magnaporthe oryzae (formerly Magnaporthe grisea) Cavara (anamorph: Pyricularia grisea (Cooke) Sacc.) (5,17, 26,27). The pathogen can infect rice plants at any growth stage from seedling through grain formation, and causes leaf blast, collar rot, nodal blast, neck blast, or panicle blast (1).

Corresponding author: Y. Jia

E-mail: yulin.jia@ars.usda.gov

The rice blast community agrees to change the name of the rice blast fungus from the former name Magnaporthe grisea to Magnaporthe oryzae at the rice blast workshop in San Diego (January 14, 2007) of the Plant and Animal Genome conference.

Commercial products are mentioned for the benefit of the reader and do not imply endorsement by the United States Department of Agriculture.

Accepted for publication 11 December 2007.

doi:10.1094/PDIS-92-4-0504

(C) 2008 The American Phytopathological Society
In the southern United States, epidemics of blast disease are erratic; thus, it is important to understand the primary source of overwintering inoculum. Seed as a primary source of $M$. oryzae inoculum has been well documented $(8,11,14)$. Research on weed hosts is important in determining the M. oryzae reservoir for a portion of genetic diversity found in rice blast populations, in studying the biology of $M$. oryzae, and in determining host specificity. $M$. oryzae causes diseases in a number of plant species, including wheat, rye grass, and pearl millet $(2,20,21,26)$. However, there has been no consensus in the literature regarding the cross-pathogenicity of Magnaporthe spp. occurring on rice and grass weeds even though Mackill and Bonman (13) reported successful cross-inoculation studies of $M$. oryzae isolates from several grass weeds and rice $(1,13,16)$.

Carolina foxtail is a winter annual grass species commonly found in moist areas of fallow fields or in wetland areas throughout most of the United States $(22,23)$. Under favorable environmental conditions or crop rotations, Carolina foxtail could occur in the same field as rice for at least part of its growth cycle. This preference for wet habitats makes it well suited to the flat, intermittently flooded agricultural fields of the southern United States that commonly are rotated between rice, soybean, and sometimes wheat. The susceptibility of Carolina foxtail to $M$. oryzae was discovered serendipitously during evaluation of rice blast disease in the greenhouse. Thus far, there have been no published studies documenting that the rice blast pathogen can infect Carolina foxtail. It is also unknown whether or not blast can infect weeds commonly present in fields rotated between rice and soybean, such as flatsedge, yellow nutsedge, hemp sesbania, northern jointvetch, and palmleaf morning glory.

The objectives of this study were to determine whether Carolina foxtail and several common weeds found in rice fields may be hosts for $M$. oryzae under favorable conditions for the pathogen.

\section{MATERIALS AND METHODS}

Plant materials and growth. Rice cvs. M202, Zhe733 (10), Katy (15), and an experimental line RU9101001 (10) were evaluated in this study. Rice seed were germinated on moist filter papers in petri dishes for 3 days in a $30^{\circ} \mathrm{C}$ dark incubator. Seedlings were transplanted to $13-\mathrm{cm}-$ diameter pots containing a sterilized DeWitt silt loam soil from Stuttgart, AR without application of fertilizer. These pots were subirrigated in a water-filled tray in a greenhouse at 24 to $30^{\circ} \mathrm{C}$ with a cycle of 16 and $8 \mathrm{~h}$ of light and darkness, respectively, for 2 weeks, until plants were at the four-leaf stage.

Carolina foxtail seed (50 to 100) were sown in small pots containing moist potting soil (Scotts-Sierra Horticultural Products Co., Marysville, OH). The pot was covered with transparent plastic film to reduce moisture loss and maintained at $25^{\circ} \mathrm{C}$ under diffuse natural sunlight near a window in the laboratory until the seed germinated (usually within 7 days). Pots containing the young seedlings then were moved to the greenhouse. Subsequently, individual seedlings were subsampled, transplanted, and grown for 3 weeks. Seedlings were grown in 13-cm-diameter pots containing sterilized Dewitt silt loam soil 
from Stuttgart, AR, without the application of fertilizer. The pots were placed in a tray that contained water. Seedlings were grown until they reached a height of 10 to
$20 \mathrm{~cm}$. Small seedlings (less than $5 \mathrm{~cm}$ tall) of Carolina foxtail were obtained from the edges of a rice paddy and were grown in a greenhouse.
Seed of several weed species commonly present in Arkansas rice or soybean fields also were obtained from local rice fields. These were rice flatsedge (Cyperus iria
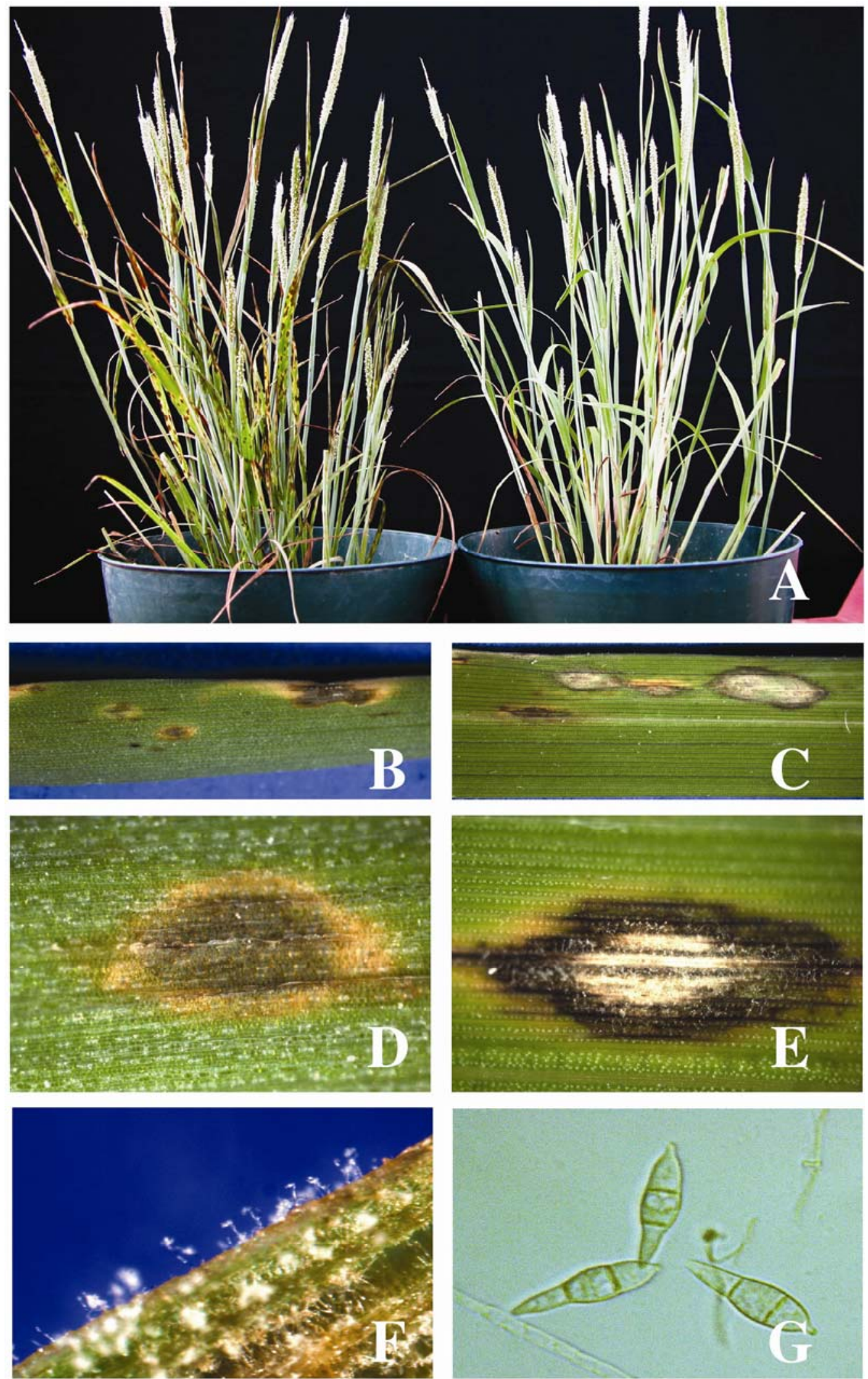

Fig. 1. Brown-spot lesions on Carolina foxtail in comparison with disease reactions of rice to Magnaporthe oryzae. A, Brown spot disease on Carolina foxtail (left pot) and noninoculated control (right pot); $\mathbf{B}$ and D, on Carolina foxtail, $\mathbf{C}$ and $\mathbf{E}$, blast lesions on 'M202' rice, $\mathbf{F}$, sporulated mycelia on Carolina foxtail, G, three M. oryzae spores and mycelia from F were magnified. A-C were taken with a Nikon digital camera; B-E were taken using a digital camera connected to a Leica Stereomicroscope; and F and G were taken with a Nikon camera DXM1200 connected to a light microscope under $\times 100$ magnification. 
L.); yellow nutsedge (C. esculentus L.); hemp sesbania (Sesbania exaltata (Raf.) Cory), northern jointvetch (Aeschynomene virginica Britton, Sterns \& Poggenb.), and palmleaf morning glory (Ipomoea wrightii A. Gray). They were grown to heights of 10 to $15 \mathrm{~cm}$ for inoculation.

Fungal isolates and culture. TM2 and $\mathrm{ZN19}$, virulent field isolates that belong to race $I E 1 k$, initially were used for this study. Cvs. Katy and M202 and line RU9100101 are susceptible (9) and Zhe 733 is resistant to TM2 (10). Subsequently, a collection of differential races of $M$. oryzae (IB 49 [ZN61], IC17 [ZN60], and assays and for verification of disease reaction on Carolina foxtail. The fungal spores were grown on filter papers and stored at $-20^{\circ} \mathrm{C}$ after desiccation. The filter papers containing fungal mycelia were placed on oatmeal agar plates (25). The inoculated plates were placed under a cycle of 16 and $8 \mathrm{~h}$ of light and darkness, respectively, at $24^{\circ} \mathrm{C}$ for 7 days. Hyphal tips were transferred to oatmeal agar (24) and cultures were incubated for an additional 12 days for production of spores.

Spore suspensions. Spores were harvested in a sterile $0.25 \%$ (wt/vol) gelatin (ICN Biomedical Inc., Costa Mesa, CA) solution by scraping fungal mycelia on the culture plates. The spore suspensions then were filtered through eight layers of cheesecloth to remove mycelia and pieces of agar (25). The concentration of the initial spore suspension was determined using a hemacytometer as described by Sambrook and Russell (18).

Pathogenicity assays. The standard pathogenicity assay was a procedure described by Valent et al. (25). Five to seven rice plants were used for each experiment. Plants were grown to the four-leaf stage in 13-cm-diameter plastic pots in a greenhouse at 24 to $30^{\circ} \mathrm{C}$ with a cycle of 16 and $8 \mathrm{~h}$ of light and darkness, respectively, and then inoculated with 2-ml spore suspensions $\left(5 \times 10^{5}\right.$ spores $\left./ \mathrm{ml}\right)$ using an airbrush (Paasche IVL double-action airbrush). Plants were inoculated inside a plastic bag that then was sealed to maintain the high humidity required for fungal penetration of IE1 [ZN4]; 4) was used for pathogenicity

the host plant cuticle (25). Plants were exposed to $24 \mathrm{~h}$ of continuous fluorescent light (10 to $12 \mu \mathrm{Em}^{-2} \mathrm{sec}^{-1}$ ) at room temperature (21 to $24^{\circ} \mathrm{C}$ ) and then the plants were removed from bags and returned to the greenhouse. Greenhouse-grown Carolina foxtail seedlings $(15 \mathrm{~cm}$ tall $)$ and mature plants of similar heights removed from the edges of a rice paddy (from April to May in Arkansas) were used for inoculation using the same procedure described above. Pathogenicity assays were repeated three times.

Disease development was monitored daily, and plants were maintained in a greenhouse at 24 to $30^{\circ} \mathrm{C}$ with a cycle of 16 and $8 \mathrm{~h}$ of light and darkness, respectively, until disease symptoms were observed for rice (7 to11 days; 24 ) and for Carolina foxtail (4 to 7 days).

\section{RESULTS}

Disease symptoms. Disease progression on Carolina foxtail was compared with disease progression on blast-susceptible cvs. Katy and M-202 and a susceptible experimental line, RU9100101. At 1 day post inoculation (dpi) with isolate TM2, no visible change was observed on inoculated rice leaves. At 2 dpi, yellow spots began to develop on Carolina foxtail, whereas brown spots appeared on the rice leaves regardless of the resistance and susceptibility to the isolates used, with the exception of the resistant cv. Zhe 733. At 3 dpi, the yellow lesions had expanded noticeably on Carolina foxtail and sporulating mycelia were not present based on observations with the unaided eye. On Katy, M202, and RU9100101, brown spots were enlarged with gray centers where faint mycelia were visible with the unaided eye. In subsequent days, yellow and watersoaked brown lesions without borders expanded on Carolina foxtail, while susceptible rice cultivars developed typical blast lesions with large gray centers (Fig 1). No symptoms were observed in the resistant cv. Zhe 733 (data not shown).

At 7 dpi, brown lesions on Carolina foxtail were readily distinguishable from blast lesions on rice, where an eye-shaped gray center normally was visible (Fig. 1A-C).

Table 1. Disease reactions of rice and Carolina foxtail to common races (isolates) of Magnaporthe oryzae $^{\mathrm{a}}$

\begin{tabular}{lccccc}
\hline & \multicolumn{5}{c}{ Host } \\
\cline { 2 - 6 } M. oryzae race (isolate) & Carolina foxtail & Zhe733 & Katy & M202 & RU9101001 \\
\hline IB49 (ZN61) & $\mathrm{S}$ & $\mathrm{R}$ & $\mathrm{R}$ & $\mathrm{S}$ & $\mathrm{S}$ \\
IC17 (ZN60) & $\mathrm{S}$ & $\mathrm{R}$ & $\mathrm{R}$ & $\mathrm{S}$ & $\mathrm{S}$ \\
IC17 (ZN57) & $\mathrm{S}$ & $\mathrm{R}$ & $\mathrm{R}$ & $\mathrm{S}$ & $\mathrm{S}$ \\
IE1 (ZN 4) & $\mathrm{S}$ & $\mathrm{R}$ & $\mathrm{R}$ & $\mathrm{S}$ & $\mathrm{S}$ \\
IE1 (ZN 49) & $\mathrm{S}$ & $\mathrm{R}$ & $\mathrm{R}$ & $\mathrm{S}$ & $\mathrm{S}$ \\
IE1k (ZN19) & $\mathrm{S}$ & $\mathrm{R}$ & $\mathrm{S}$ & $\mathrm{S}$ & $\mathrm{S}$ \\
IE1k (TM2) & $\mathrm{S}$ & $\mathrm{R}$ & $\mathrm{S}$ & $\mathrm{S}$ & $\mathrm{S}$ \\
\hline
\end{tabular}

${ }^{a}$ Disease reactions were determined using the method described in Valent (27). The data represent overall visual ratings from three independent experiments; $\mathrm{S}=$ susceptible and $\mathrm{R}=$ resistant.

${ }^{\mathrm{b}}$ Fungal isolates were differential races commonly found in the southern rice-growing areas in the United States (4).
In contrast to rice, conidiospores on Carolina foxtail were visible only under bright light examined by the use of microscopes after diseased leaves were incubated for 1 to 3 days on moistened filter papers in a petri dish (Fig. 1F and G).

The susceptibility of Carolina foxtail to $M$. oryzae was discovered serendipitously during evaluation of rice blast disease in the greenhouse. Rice flatsedge, yellow nutsedge, hemp sesbania, northern jointvetch, and palmleaf morning glory also were inoculated with TM2. None of them supported $M$. oryzae growth like Carolina foxtail. No visible responses were observed even at 10 dpi (data not shown).

Race reactions. The different isolates of $M$. oryzae were verified first by fingerprinting using Rep-polymerase chain reaction (PCR) (data not shown); reactions of Carolina foxtail to these isolates are summarized in Table 1. Uniformly, Carolina foxtail was susceptible to five races (seven isolates) tested and the disease reaction was comparable with the most susceptible experimental line RU9101001 and cv. M202. By comparison, Katy was susceptible to some isolates and Zhe733 was resistant to all isolates. IE1k was the most virulent race for all rice cultivars except Zhe733. The disease symptoms on Carolina foxtail appeared 1 day faster after inoculation with IE1k than with the other races.

To verify that there was no differential reaction within Carolina foxtail, seed produced from plants grown in the greenhouse and field plots from Stuttgart, AR from 2001 to 2005 were germinated and analyzed using the seven isolates. Consistently, all Carolina foxtail were uniformly susceptible (data not shown). We concluded that there was no differential reaction of Carolina foxtail to differential races of rice blast fungus tested.

Cross-infection. Isolate TM2, belonging to race IE1k which infects Katy, was used for cross-infection. The spores were isolated from infected Carolina foxtail leaves (Fig. 1A-G), and these isolates were verified using Rep-PCR to be the same isolate IE1k initially used to inoculate Katy (data not shown). Due to limited sporulation, it was extremely difficult to recover spores from anywhere on infected leaves of Carolina foxtail. The extent of virulence with similar disease lesions on rice cultivars is identical to that of the original isolate TM2 after the same length of time post inoculation (data not shown). Passage of isolates through Carolina foxtail does not affect their pathogenicity on rice based on the fact that the same disease reaction was obtained on rice using conidia from foxtail as with conidia of the same race obtained from culture.

\section{DISCUSSION}

$M$. oryzae is one of the most deadly airborne pathogens of cereal crops. Resis- 
tance to the pathogen has been characterized to be a gene-for-gene system (610,19). The pathogen utilizes diverse hosts for overwintering, and multiple means of transmission (seed and wind-dispersed spores) are strategies for the pathogen's survival $(6,11-13)$. We have demonstrated that $M$. oryzae races that infect rice also could infect a widespread winter annual weed in the United States, Carolina foxtail, causing brown spots that are different from typical blast symptoms. In contrast, other common weeds found in rice fields, rice flatsedge, yellow nutsedge, hemp sesbania, northern jointvetch, and palmleaf morning glory did not develop symptoms when inoculated with $M$. oryzae. These findings suggest that $M$. oryzae potentially could use Carolina foxtail as a host between rice crops.

Adaptability is a characteristic of $M$. oryzae (28). Successful cross-infection previously performed with grass weeds by Mackill and Bonman (13) is an important demonstration of this adaptability. It is known that $M$. oryzae is the causal agent for many gramineous plants with specificity within several subgroups. However, it also is known that the blast fungus can damage plant species that are not known as primary hosts. For example, recent destructive epidemics of blast diseases were found on perennial ryegrass (Lolium perenne; 2) and on wheat (Triticum aestivum; 21). Carolina foxtail is closely related to blackgrass (Alopecurus myosuroides Huds.), a highly competitive and problematic weed of winter wheat in Europe (3). It is worthwhile to examine whether blackgrass can be a host of $M$. oryzae under favorable conditions for the pathogen.

Planting time for rice has shifted recently from April to March in Arkansas to save water and to increase yield. The earlier that rice is planted, the greater would be the overlap of rice and Carolina foxtail growth cycles and the more likely that the blast pathogen could be exchanged between these two plant species. Our results reveal that the brown spot symptoms on Carolina foxtail are quite distinct from those of typical blast symptoms. Lack of previous published reports of blast on Carolina foxtail could be attributable to no studies having been conducted on this weed species and, more straightforwardly, blast on Carolina foxtail may have been overlooked previously because the disease symptoms look significantly different from those on rice and other hosts. Successful isolation of $M$. oryzae from lesions on Carolina foxtail and infection of rice by these isolates is indisputable evidence that the fungus is a pathogen of Carolina foxtail and causes brown spot disease symptoms under favorable conditions. Research should be initiated worldwide to determine whether Carolina foxtail could be a host for $M$. oryzae in nature.

\section{ACKNOWLEDGMENTS}

We thank the University of Arkansas Rice Research and Promotion Board for support to $\mathrm{L}$. Wu and M. J. Lin; M. H. Jia for proofreading; J. Correll and $\mathrm{K}$. Moldenhauer for providing the fungal isolates and rice seed, respectively; anonymous reviewers; M. McGrath for critical readings; J. Gibbons for helpful discussions on crop systems in Arkansas; and K. Gubrji and L. Bernhardt for excellent technical support.

\section{LITERATURE CITED}

1. Asuyam, H. 1963. Morphology, taxonomy, host range and life cycle of Pyricularia oryzae. Pages 9-22 in: The Rice Blast Disease. S. H. Ou, ed. The John Hopkins Press, Baltimore, MD.

2. Bain, D. C., Patel, B. M., and Patel, M. V. 1992. Blast of ryegrass in Mississippi. Plant Dis. Rep. 56:210

3. Chauvel, B., Guillemin, J. P., Colbach, N., and Vaquez, J. 2001. Evaluation of cropping systems for management of herbicide-resistant populations of blackgrass (Alopecurus myosuroides Huds.). Crop Prot. 20:127-137.

4. Correll, J. C., Harp, T. L., Guerber, J. C., and Lee, F. N. 2000. Differential changes in host specificity among MGR586 DNA fingerprint groups of Pyricularia grisea. Pages 234-242 in: 2nd Int. Symp. Rice Blast Dis. D. Tharreau, ed. Kluwer Academic Press, Dordrecht, The Netherlands.

5. Couch, B. C., and Kohn, L. M., 2002. A multilocus gene genealogy concordant with host preference indicates segregation of a new species, Magnaporthe oryzae, from M. grisea. Mycologia 94:683-693.

6. Farr, D. F., Bills, G. F., Chamuris, G. P., and Rossa, A. Y. 1989. Fungi on Plants and Plant Products in the United States. American Phytopathological Society, St. Paul, MN.

7. Godwa, M., Venu, R. C., Roopalakshmi, K., Sreerekha, M. V., and Kulkarni, R.S. 2003. Advances in rice breeding, genetics and genomics. Mol. Breed. 11:337-352.

8. Guerber, C., and TeBeest, D. O. 2006. Infection of rice seed grown in Arkansas by Pyricularia oryzae and transmission to seedlings in the field. Plant Dis. 90:170-176.

9. Jia, Y., Wamishe, Y., Jia, M. H., Lin, J., Eizenga, G. C., Gibbons, J. W., Moldenhauer, K. A. K., and Correll, J. C. 2005. Two major resistance genes confer resistance to rice shift isolates overcoming blast resistance gene $\mathrm{Pi}$ ta. Pages 91-95 in: B. R. Wells Rice Research Studies Series 529. R. J. Norman, J. F. Meullenet, and K. A. K. Moldenhauer, eds. University of Arkansas Agricultural Experiment Station Research, Fayetteville.

10. Jia, Y., Wang, Z., Fjellstrom, R. G., Moldenhauer, K. A. K., Azam, M. A., Correll, J., Lee, F. N., Xia, Y., and Rutger, J. N. 2004. Rice Pita gene confers resistance to the major pathotypes of the rice blast fungus in the United States. Phytopathology 94:296-301.
11. Lamey, H. A. 1970. Pyricularia oryzae on rice seed in the United States. Plant Dis. Rep. 54:931-935.

12. Lee, F. N. 1994. Spore sources for rice blast epidemics. Ark. Farm Res. 43:4-5.

13. Mackill, A. O., and Bonman, J. W. 1986. New Hosts of Pyricularia oryzae. Plant Dis. 70:125-127.

14. Manandhar, H. K., Lyngs Jorgensen, H. J., Smedegaard-Petersen, V., and Mature, S. M. 1998. Seedborne infection of rice by Pyricularia oryzae and its transmission to seedlings. Plant Dis. 88:1084-1099.

15. Moldenhauer, K. A. K., Lee, F. N., Norman, R J., Helms, R. S., Well, R. H., Dilday, R. H., Rohman, P. C., and Marchetti, M. A. 1990 Registration of 'Katy' rice. Crop Sci. 30:747748.

16. Ou, S. H. 1972. Rice Diseases. Commonwealth Mycological Institute, Kew, Surrey, UK.

17. Rossman, A. Y., Howard, R. J., and Valent, B. 1990. Pyricularia grisea, the correct name for the rice blast fungus. Mycologia 82:509-512.

18. Sambrook, J., and Russell, D. W., eds. 2001. Estimation of cell number. A8.6 in: Molecular Cloning: A Laboratory Manual. Cold Spring Harbor Laboratory Press, Cold Spring Harbor, NY.

19. Silue, D., Nottenghem, J. L., and Thorreau, D. 1992. Evidence for a gene-for-gene relationship in the Oryza sativa-Magnaporthe grisea pathosystem. Phytopathology 82:577-580.

20. Sundaram, N. V., Palmer, L. T., Nagarajan, K., and Prescott, J. M. 1972. Disease survey of sorghum and millet in India. Plant Dis. Rep. 56:740-743.

21. Urashima, A. S., Igarashi, S., and Kato, H. 1993. Host range, mating type, and fertility of Pyricularia grisea from wheat in Brazil. Plant Dis. 77:1211-1216.

22. USDA. 2005. Midwestern wetland flora: Field office guide to plant species. U.S. Dep. Agric. Soil Conservation Service, Midwest National Technical Center, Lincoln, NE. Jamestown, ND: Northern Prairie Wildlife Research Center Home Page.

23. USDA, NRCS. 2005. The PLANTS Database, version 3.5 (http://plants.usda.gov). Data compiled from various sources by Mark W. Skinner. National Plant Data Center, Baton Rouge, LA.

24. Valent, B. 1997. The Rice Blast Fungus, Magnaporthe grisea. Plant Relationships. Pages 37-54 in: The Mycota, V Part B. G. C. Carroll and P. Tudzynoski, eds. Springer-Verlag, Berlin, Heidelberg.

25. Valent, B., Farrall, L., and Chumley, F. G. 1991. Magnaporthe grisea genes for pathogenicity and virulence identified through a series of backcrosses. Genetics 127:87-101.

26. Webster, R. K., and Gunnell, P. S. 1992. Rice blast. Pages 14-17 in: Compendium of Rice Diseases. R. K. Webster and P. S. Gunnell, eds. American Phytopathological Society, St. Paul, $\mathrm{MN}$.

27. Yaegashi, H., and Udagawa, S. 1978. The taxonomical identity of the perfect state of Pyricularia grisea and its allies. Can. J. Bot. 56:180-183.

28. Zhou, E., Jia, Y., Correll, J., and Lee, F. N. 2007. Instability of the Magnaporthe oryzae avirulence gene AVR-Pita alters virulence. Fungal Genet. Biol. 44:1024-1034 